\title{
Editorial
}

\section{Some Unanswered Questions in Re-stenosis Prevention Research}

There is large amount of evidence for reducing cardiovascular events and inhibiting progression of atherosclerosis by statin therapy (1). On the other hand, most prior trials have failed to demonstrate the preventive effect of statins on restenosis after $\mathrm{PCl}$ except for early, small clinical studies (2). In addition, the recent introduction of drug eluting stents in clinical practice has reduced interest in restenosis prevention trials using a systemic pharmacological approach. However there are still some areas where clinical data is lacking in the field of restenosis prevention research. Restenosis after self expandable stent implantation for acute coronary syndrome is one of these areas.

Concerning this issue, Nishikawa et al. provided new evidence of the inhibitory effect of statin treatment on restenosis after self-expandable stent implantation in acute coronary syndrome (3). The restenosis rate was $11 \%$ and the TLR was $8 \%$ in the statin group. It was highly effective and suggested the potential of combination therapy with self-expandable stents and statins for restenosis prevention in acute coronary syndrome. The efficacy of statin in this study may be related to plaque characteristics in acute coronary syndrome and the grade of vascular injury by self-expandable stent delivery. Soft plaques in acute coronary syndrome usually show a higher degree of inflammatory cell proliferation. Self-expandable stents may provide a bigger gain in lumenal size with lower acute vascular injury. Thus, this particular clinical subset may be receptive to statin therapy for restenosis prevention as compared to the subset in which prior trials had challenged. However, the current status of the use of self-sxpandable stents is quite limited and there has been intensive discussion of the role of these stents regarding the degree of chronic vascular injury (4). Further studies are needed to confirm this efficacy.

As the levels of LDL cholesterol at 6 months were similar between the two groups, the authors suggested that the direct anti-inflammatory, anti-proliferative and/or anti - thrombotic effects of statin played an important role in restenosis prevention in this study. Indeed the restenosis process involves several inflammatory and proliferative vascular reactions not related to the levels of LDL cholesterol, which is more prominent in acute coronary syndromes. It was shown that a high concentration of statin could directly reduce intimal thickening after vascular injury in several animal models (5). Thus, it is possible that statin could inhibit these pathways in certain clinical subsets such as acute coronary syndrome treated by selfexpandable stents. It would be helpful to further understand the role of statin in restenosis prevention described in this manuscript, particularly if authors could provide detailed QCA results such as reference vessel diameter, acute gain and late loss in relation to LDL cholesterol levels.

\section{References}

(1) Cholesterol Treatment Trialists' (CTT) Collaborators. Lancet, 366: 1267-1278, 2005

(2) Serruys PW, Foley DP, Jackson G, Bonnier H, Macaya C, Vorolix M, Branzi A, Shepherd J, Suryapranata $H$, de Felter PJ, Melkert R, van Es $\mathrm{GA}$, and Pfister PJ: A randomized placebo-controlled trial of fluvastatin for prevention of restenosis after successful coronary balloon angioplasty; final results of the fluvastatin angiographic restenosis (FLARE) trial. Eur Heart J. 20: 58-69, 1999

( 3 ) Nishikawa $H$, Miura S, Shimomura H, Kawamura A, Tsujita K, Shirai K, Matsuo K, Arai H, and Saku K: Effect of Statin on Restenosis after Radius Stent Implantation in Patients with Acute Coronary Syndrome. J Atheroscler Thromb, 12: 302-306, 2005

( 4 ) Kobayashi Y, Honda Y, Christie LG, Teirstein PS, Bailey SR, Brown CL 3rd, Matthews RV, DeFranco AC, Schwartz RS, Goldberg S, Popma JJ, Yock PG, and Fitzgerald PJ: Long-term vessel response to a self-expanding coronary stent: a serial volumetric intravascular ultrasound analysis from the ASSURE Trial. A stent vs. Stent Ultrasound Remodeling Evaluation. J Am Coll Cardiol. 37: 1329-1343, 2001

( 5 ) Bellosta S, Bernini S, Ferri N, Quarato P, Canavesi M, Arnaboldi L, Fumagalli R, Paoletti R, and Corcini A: Direct vascular effects of HMG-CoA reductase inhibitors. Atheroscrelosis, 137 (suppl): S101-S109, 1998

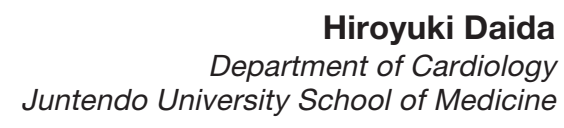

